Editor-in-Chief Mandeep S Dhillon

\section{Journal of Postgraduate Medicine Education and Research}

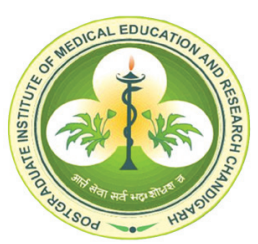

The Official Journal of

Postgraduate Institute of Medical

Education and Research, Chandigarh, India

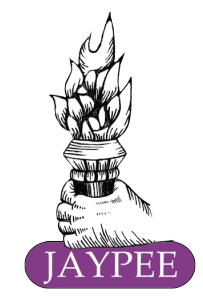

www.jaypeebrothers.com

www.jaypeejournals.com 
Editor-in-Chief Mandeep S Dhillon

Associate Editors

Dheeraj Khurana

Surinder Rana

Sarvdeep S Dhatt

Ramandeep Virk

Assistant Editors

Shalini Gainder

Sandeep Bansal

Editorial Coordinator Kusum Rana

Publishing Center

Publisher

Jitendar P Vij

Business Head

Geetika Sareen

Managing Editor

Maryam Khan

\section{Editorial and Production Office}

PS Ghuman

Journals Department

Jaypee Brothers Medical Publishers (P) Ltd.

4838/24, Ansari Road, Daryaganj

New Delhi-110 002, India

Phone: +91-11-43574357, +91-9958882255, +91-9717528877

Fax: +91-11-43574314

e-mail: journals@jaypeebrothers.com

ps.ghuman@jaypeebrothers.com

\section{Advertisements/ Subscriptions/ Reprints}

Ashwani Shukla

Phone: +91-8447136447

e-mail: advertisements@jaypeejournals.com

e-mail: subscriptions@jaypeebrothers.com

ashwani.shukla@jaypeebrothers.com

For Website Queries

Phone: +91-11-43574357

e-mail: contact@jaypeejournals.com

\section{INTERNATIONAL EDITORIAL ADVISORY BOARD}

Ajay Sandhu, California, USA

(Radiation Medicine and Applied Sciences)

Anupam Aggarwal, Alabama, UK (Nephrology)

Kapil Sethi, Georgia, USA (Neurology)

Patrick S Kamath, Minnesota, USA (Medicine)

Pravin C Singal, New York, USA (Medicine)

Sanjay Suri, Ontario, Canada (Dentistry)

Suresh T Chari, Minnesota, USA (Medicine)

Vikas Khanduja, Cambridge, UK (Orthopedics)

Vikas Prasad, Berlin, Germany (Nuclear Medicine)

\section{NATIONAL EDITORIAL ADVISORY BOARD}

Adarsh Kohli (Psychiatry)

Aman Sharma (Internal Medicine)

Ashima Goel (Oral Health Sciences)

Ajay Duseja (Hepatology)

Ashish Jain (Transfusion Medicine)

Ajay Salvania (General Surgery)

Baljinder Singh (Nuclear Medicine)

Deepti Suri (Paediatrics)

Jerry R. John (Plastic Surgery)

L. Kaman (General Surgery)

Monika Bawa (Paed. Surgery)

Man Updesh Singh (Haematology)

Nusrat S. (Pharmacology)

Nandita Kakkar (Histopathology)

Paramjit Singh (Radiodiagnosis)

Parag Barwad (Cardiology)

Ravindra Khaiwal (School of Public Health)

Rakesh Kapoor (Radiotherapy)

Reema Bansal (Ophthalmology)

Sunil Dogra (Dermatology)

Sanjay Bhadada (Endocrinology)

Sahajal Dhooria (Pul. Medicine)

S.S.Dhandapani (Neuro. Surgery)

Sukhpal Kaur (NINE)

Tulika Gupta (Anatomy)

Tanvir Samra (Anaesthesia)

Vikas Suri (Internal Medicine)

Y.S. Bansal (Forensic Medicine)

Divya Dahiya (General Surgery) 


\section{Editorial}

\section{The Essence of Practice of Medicine: Is it Science of Evidence Based Medicine or Art of Clinical Medicine?}

The field of medicine has seen a sea of change in the way we teach and practice medicine. The technological advancement has transformed medicine from a clinical bedside art to a field of sophisticated equipment and gadgets. Simultaneously, the principles of finance and management have percolated into the practice of medicine with hospitals and physicians being considered as service providers. Increased reliance on gadgets and equipment have decreased the humane touch and compassion, a principle that was so fundamental in treating sick patients. We have started believing that medicine is evidence based pure science and health care is a business and this has led on to a vital blow to the patient doctor relationship as well as art of clinical medicine.

India is also witnessing similar changes in the practice of medicine over last 2 decades and there are increased concerns on the gradual decline of art of clinical medicine. Earlier the Indian health care was primarily driven by the individual clinical expertise and experience of the physician. However, in-face of increased medico-legal aspects as well as increased and wide availability of sophisticated equipment's, the clinical practice is gradually shifting from clinical expertise to evidence-based medicine (EBM). In 1991, EBM word was 1st time coined by Gordon H Guyatt as 'the conscientious, explicit, and judicious use of current best evidence in making decisions about the care of individual patients. ${ }^{1}$ EBM provides more dedicated, systemic and homogenous pathway for making clinical decision for patient's management. When EBM was envisaged, its objective was not to replace the clinical expertise-based decision but rather to help it with objective evidence. ${ }^{2}$ However, in recent years there has been overreliance on EBM over clinical expertise and experience leading on to concerns about the gradual death of art of clinical medicine.

From its inception, EBM has remained in controversies as many of the leading physicians considered it as a 'cookbook medicine' and considered it to be inferior to the clinical expertise. ${ }^{3}$ EBM mainly relies on various clinical trials to produce data regarding particular disease and management protocol. However, many trials from which EBM is formulated have been found to be suffering from major limitations like poor methodology and study design, suboptimal power of study or non-representative study cohort. Moreover, on many occasions, reliability of the data has also been questioned by world's leading physicians. Ioannidis JP et al., reviewed 49 highly cited articles (cited more than 1000 times) from 3 leading medical journals. ${ }^{4}$ Forty five studies claimed that the intervention was effective and of these, $7(16 \%)$ studies were contradicted by subsequent studies and only $11(24 \%)$ studies remained unchallenged. They concluded that controversies are not only common with highly cited nonrandomized studies, but even highly cited randomized trials may be challenged and refuted over time. ${ }^{4}$ In recent years many articles have shown contradictory and opposite results making decisions based on such evidence difficult. Moreover, influence of various drug companies on major clinical trials has sometimes raised questions on reliability of various clinical trials. ${ }^{5}$

Also, the medical literature has seen an exponential rise in meta-analysis or systemic review of various topics. However, many times, the studies included in meta-analysis or systemic reviews are themselves underpowered studies making it an unfruitful exercise. Moreover, in recent years many meta-analysis on the same topic have been published and this leads on to confusion. One recent article has shown that annual publications between 1991 and 2014 has increased 2,728\% for systematic reviews and 2,635\% for meta-analyses versus only 153\% for all PubMedindexed items. ${ }^{6}$ And, contradictory results even in meta-analysis increases the confusion on management.

Despite EBM being suffering from these important flaws, it has now become an indispensable part of current medical practice. We as a clinician should always remember that EBM is meant for supplementing the clinical experience and expertise, not to replace it. Critical review of an article or meta-analysis including understanding the study designs, study population and results is of utmost important before coming to any conclusion and modulating the clinical practice. There are three basic pillars for practicing EBM more rationally: clinical examination or expertise, current best evidence and patient's desire or patient's best interest. All three pillars are indispensable for effective clinical practice and ideally, they all should be integrated for better clinical outcome. In practicing EBM, modulating current evidence according to the local scenario or available resources to maintain patient's best interest is of utmost importance especially in resource limited country like India. As the routine challenges faced in India is quite different from challenges faced by majority of developed countries, modulating best current evidence according to local scenario or available resources is of utmost importance to achieve best clinical outcome. 
To summarize, clinical expertise and evidence both are an important part of today's medical practice. Understanding limitation and strengths of each evidence is of utmost importance before its application. EBM should always be backed up by sound clinical knowledge and expertise. Both clinical expertise and EBM are required for effective patient management and they should be integrated to provide an ultimate goal of health of patient. In our opinion, modern age physicians, along with acquisition of knowledge of medical science also need to learn and nurture the art of clinical medicine that involves treating patients with compassion and humane touch.

\section{REFERENCE}

1. Szajewska H. Evidence-Based Medicine and Clinical Research: Both Are Needed, Neither Is Perfect. Ann Nutr Metab 2018; 72 : $13-23$.

2. Godlee F. Milestones on the long road to knowledge. BMJ 2007; 334 Suppl 1: s2-3.

3. Charlton BG. Restoring the balance: evidence-based medicine put in its place. J Eval Clin Pract 1997; 3: 87-98.

4. Ioannidis JPA. Contradicted and initially stronger effects in highly cited clinical research. JAMA 2005; 294: 218-228.

5. Angell M. Drug Companies \& Doctors: A Story of Corruption. 2009.https://www.nybooks.com/articles/2009/01/15/drugcompanies-doctorsa-story-of-corruption/ (accessed 12 Jan2019).

6. Ioannidis JPA. The Mass Production of Redundant, Misleading, and Conflicted Systematic Reviews and Meta-analyses. Milbank Q 2016; 94: 485-514.

Jimil Shah, Surinder Singh Rana Department of Gastroenterology Postgraduate Institute of Medical Education and Research (PGIMER)

Chandigarh, India-160023 Address for Correspondence: Prof Surinder S Rana, MD, DM, FASGE Department of Gastroenterology, Postgraduate Institute of Medical Education and Research (PGIMER) Chandigarh-160012 


\title{
Journal of Postgraduate Medicine Education and Research
}

\author{
January-March 2019 Volume 53 Number 1
}

\section{Contents}

\section{ORIGINAL ARTICLES}

- A Cross-sectional Study of Prevalence and Correlates of Tobacco Use in Three Districts of Punjab, India

Garima Bhatt, Sonu Goel, Suman Mor, Rakesh Gupta

- Drug-induced Acute Kidney Injury/Acute Tubulointerstitial Nephritis: A Clinico-etiological Study from a Single Center in North-east India

Manjuri Sharma, Manzoor A Parry, Pranab J Mahanta, Prodip Doley, Gayatri Pegu, Hamad Jeelani

- Effect of Extent of Hippocampal and Amygdala Resection on Seizure Outcome in Patients with Refractory Epilepsy Secondary to Medial Temporal Sclerosis

Sachin Bindal, Navneet Singla, Parampreet Singh, Manish Modi, Kokkula Praneeth, Manju Mohanty,

Sameer Vyas, Sunil K Gupta

\section{REVIEW ARTICLES}

- Accelerating Adoption of Artificial Intelligence in Healthcare Amarjeet Singh, Siddharth Angrish

- Adverse Drug Reactions to Disulfiram Treatment with or without Alcohol Challenge in the Indian Setting: Systematic Review

Jaison Joseph, Debasish Basu

\section{CASE REPORTS}

- An Extremely Unusual Case of Type A Interrupted Aortic Arch in a Young Male Uma Debi, Prem Kumar, Manphool Singhal, Manoj Rohit

- Maxillofacial Reconstruction with Patient-specific Implants Vidya Rattan, Sachin Rai, Satnam S Jolly, Vijay K Meena

- Post-surgical Extraoral Commissure Stent for Correction of Microstomia in a Child with Chemical Burns: A Clinical Report

Nidhi Mangtani, Gunjan Pruthi, Veena Jain

\section{BRIEF COMMENTARY ON MEDICAL EDUCATION}

- Authentic Assessment in Medicine. $42-44$ Shalini Gupta

\section{BIOSTATISTICS SERIES}

- Statistics Corner: Measurement Scales $45-46$ Kamal Kishore, Rakesh Kapoor

\section{CLINICOPATHOLOGICAL CONFERENCE REPORT (CPC)}

- Lupus Flare in Pregnancy 47-58 Ritambhra Nada, Manoj G Madakshira, Shefali Sharma, Tulika Gupta, Vanita Suri, Savita Kumari 


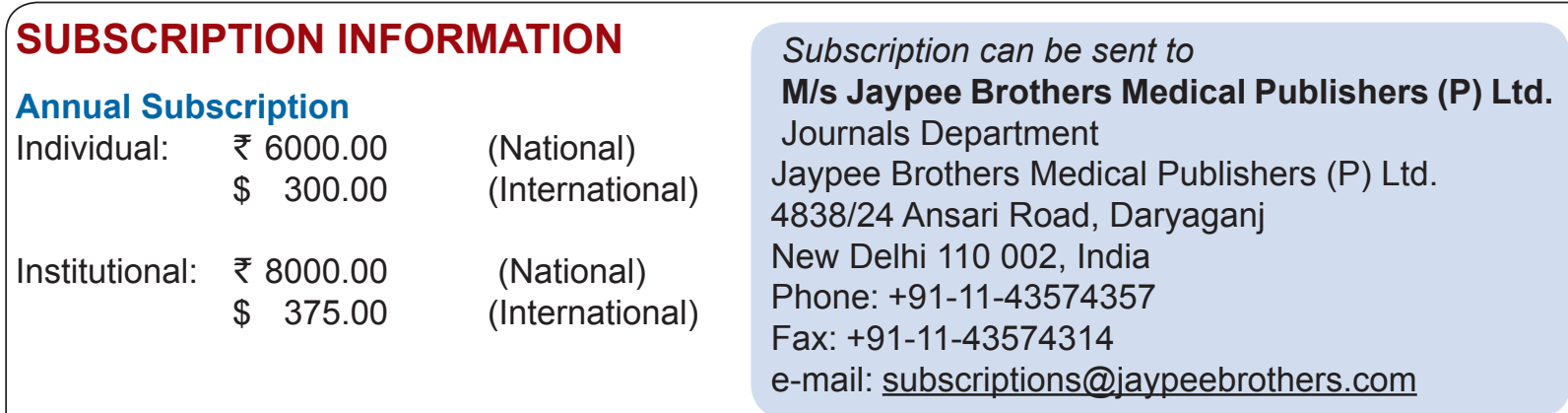

This journal is published quaterly in a year, i.e. January, April, July and October. Dollar rates apply to subscribers in all the countries except India where INR price is applicable. All subscriptions are payable in advance and all the rates include postage. Journals are sent by air to all the countries except Indian subcontinent. Subscriptions are on an annual basis, i.e. from January to December. Payment will be made by dollar cheque, credit card or directly through our bank account at the following address:
1. Our Banker's Name:
2. Our Current $A / c$ No:
ICICI Bank Ltd.
3. Amount to be Transferred in the Name of:
4. IFSC Code:
JAYBRZ
JAYPEE BROTHERS MEDICAL
PUBLISHERS (P) LTD., NEW DELHI
ICIC0000106

For further queries, please do not hesitate to contact at subscriptions@jaypeebrothers.com

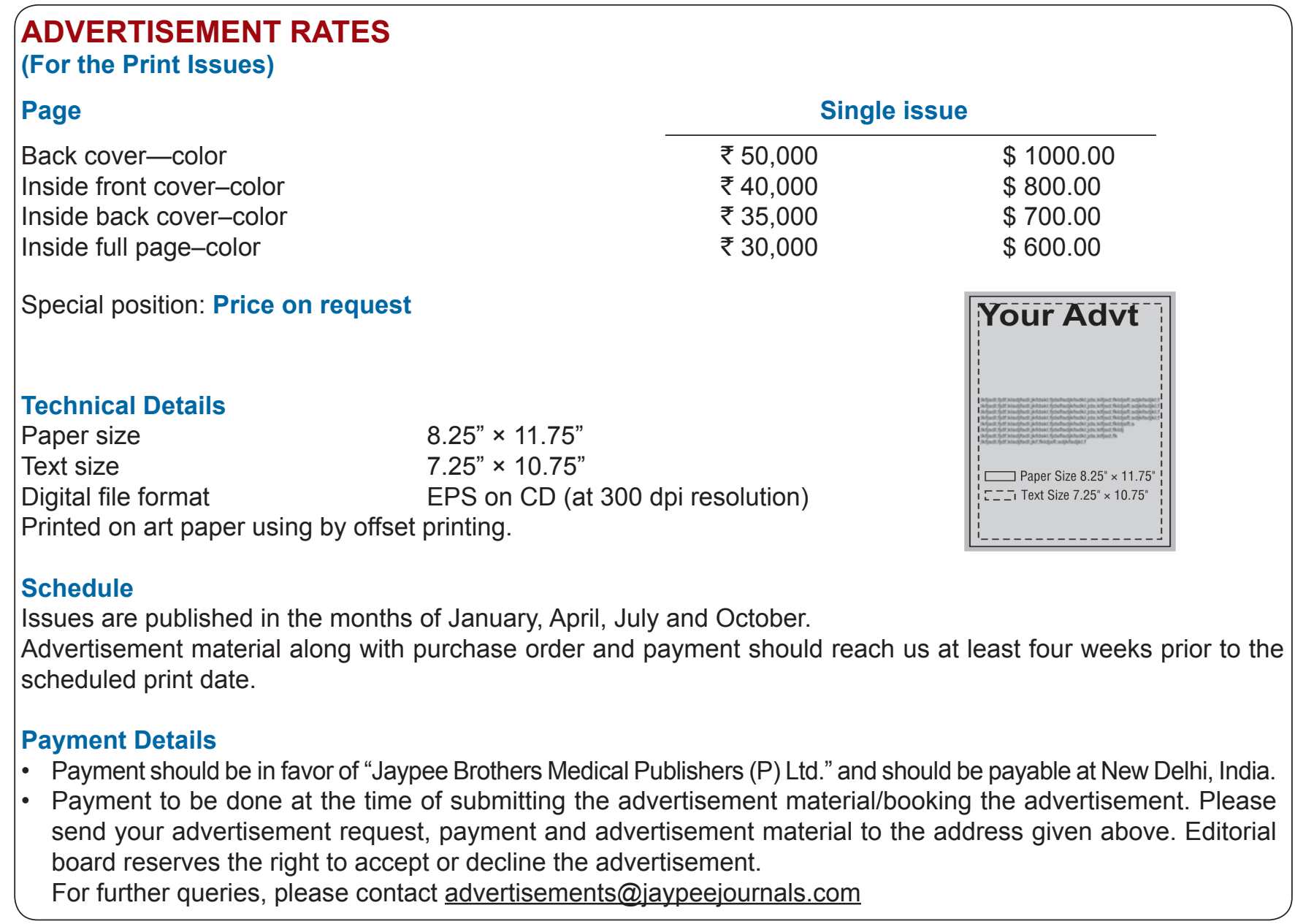

